\title{
Preventing Financial Strain for Low- and Moderate-Income Adults: a Comparison of Medicaid, Marketplace, and Employer-Sponsored Insurance
}

\author{
Sonali Saluja, $\mathrm{MD}, \mathrm{MPH}^{7} \odot$, Cameron Kaplan, $\mathrm{PhD}^{7}$, Pooja Dhupati, $\mathrm{MPH}^{2}$, and \\ Danny McCormick, MD, MPH ${ }^{3}$ \\ 'Gehr Center for Health Systems Science and Innovation, Keck School of Medicine of University of Southern California, Los Angeles, CA, USA; \\ ${ }^{2}$ Department of Preventive Medicine, Keck School of Medicine of University of Southern California, Los Angeles, USA; ${ }^{3}$ Cambridge Health Alliance, \\ Cambridge Massachusetts and Harvard Medical School, Boston, MA, USA.
}

\begin{abstract}
BACKGROUND: Medicaid expansion and subsidized private plans purchased on the Affordable Care Act's (ACA) Marketplaces accounted for most of the ACA's coverage gains.

OBJECTIVE: Compare access to care and financial strain between Medicaid and Marketplace plans, and benchmark these against employer-sponsored insurance (ESI) plans.
\end{abstract}

DESIGN: Cross-sectional survey

PARTICIPANTS: A nationally representative, noninstitutionalized sample of 37,219 non-elderly adults with incomes up to $400 \%$ of the federal poverty level between 2015 and 2018, and a sub-group of individuals with chronic diseases.

MAIN MEASURES: Self-reported barriers to accessing care, cost-related medication non-adherence, and financial strain.

KEY RESULTS: Marketplace enrollees were more likely than Medicaid enrollees to delay or avoid care due to cost (19.3\% vs 10.0\%; adjusted difference (AD), 8.6 [95\% CI, 6.8 to 10.4$]$ ) and report difficulties affording specialty care (7.7\% vs 6.6\%; $\mathrm{AD}, 1.8 \%$ [95\% CI, $0.3 \%$ to $3.3 \%]$ ), while there were no differences in having insurance accepted by a doctor or ability to afford dental care. Marketplace enrollees were also more likely to report cost-related medication non-adherence (21.5\% vs $20.0 \%$; AD, 4.0 [CI, 1.5 to 6.4$]$ ), be very worried about not being able to pay medical costs in case of a serious accident (32.3\% vs $25.8 \%$; $\mathrm{AD}, 6.4$ [CI, 4.2 to 8.6]), have expenses exceeding $\$ 2000$ (22.4\% vs $5.4 \%$; AD, 8.3 [CI, 6.2 to 10.3$]$ ), and have problems paying medical bills (18.4\% vs $15.6 \%$; AD, $1.8[\mathrm{CI}$, 0.3 to 3.9]). Marketplace-Medicaid differences were larger among persons with a chronic disease. Individuals in ESI plans fared better for most, but not all, outcomes.

CONCLUSION: Medicaid offers better protections than Marketplace plans on most measures of access and financial strain.

J Gen Intern Med 37(10):2373-81

DOI: $10.1007 / \mathrm{s} 11606-021-07100-0$

(c) Society of General Internal Medicine 2021

Prior presentations None

Received March 23, 2021

Accepted August 13, 2021

Published online September 15, 2021

\section{INTRODUCTION}

The Affordable Care Act (ACA) resulted in substantial improvements in access to care and medically induced financial hardships. ${ }^{1-6}$ Gains were largest for low- and moderateincome Americans and those with chronic medical conditions. ${ }^{7}$ The ACA's Medicaid expansion, providing coverage to individuals with incomes up to $138 \%$ of the federal poverty level (FPL) (in states that implemented the expansion), and subsidized private Marketplace plans, available for individuals with incomes between $138 \%$ (100\% in non-expansion states) and $400 \%$ of the FPL, accounted for most of its coverage gains. ${ }^{8}, 9$ President Biden has proposed expanding health insurance coverage for low- and moderate-income individuals through a "public option" 10 and has recently signed the American Rescue Plan (ARP) which temporarily extends premium tax credits for Marketplace plans to higher-income groups and increases subsidies to those who already qualify. ${ }^{11}$ Understanding how these coverage options affect enrollees' access to care and medically induced financial strain could inform future decisions about whether to utilize public versus publicly subsidized private insurance plans to expand coverage; it is also salient as millions of Americans have lost employersponsored insurance (ESI) during the COVID-19 pandemic $^{12}$ and enrollment in both Marketplace plans and Medicaid has increased substantially. ${ }^{13,14}$

Medicaid generally requires no premium payments and no or minimal cost sharing (i.e., deductibles and co-pays). Marketplace plans, in contrast, usually require premium payments and cost sharing, as is typical of most private health plans. Prior to the temporary augmentation of financial assistance for Marketplace enrollees under the ARP, individuals with incomes below $400 \%$ of the FPL were eligible to receive premium tax credits (the amount depending on income) and those with incomes between 100 and $250 \%$ of the FPL received cost-sharing reduction subsidies. However, previous studies have raised concerns about the affordability of care under such plans. ${ }^{15-20}$ Medicaid and Marketplace enrollees differ in important ways. Marketplace enrollees typically have more 
assets and a lower burden of disease than those with Medicaid, suggesting that Medicaid recipients may have a greater need for care and find health care costs more burdensome. However, the adverse effects of Marketplace plans' design may outweigh the advantages of greater wealth and better health. Previous analyses comparing access to care and health care spending before and after the ACA, for Medicaid- and Marketplace-eligible individuals ${ }^{21,22}$ and actual enrollees, ${ }^{23-}$ ${ }^{25}$ have yielded mixed results. These studies, however, have only examined pre-post-ACA changes in a subset of lowincome individuals (those with incomes between 100 and $138 \%$ of the FPL), ${ }^{21}, 22,25$ populations with moderate or severe psychological distress,${ }^{24}$ or residents of a single state. ${ }^{23}$,

${ }^{25} \mathrm{We}$ are unaware of nationally representative studies comparing health care accessibility and medical financial burdens for Medicaid and Marketplace enrollees in the post-ACA period across the income spectrum of individuals enrolled in these plans $(0-400 \%$ of the FPL) or among individuals with chronic diseases, a group with significant health care needs and greater health care spending. ${ }^{26}$

We analyzed nationally representative, cross-sectional data on access to care and medical financial strain of low- and moderateincome persons, comparing Medicaid and Marketplace plan enrollees (at the time they were surveyed); we also compared them to individuals with ESI, often considered to be the gold standard for health insurance coverage. We replicated these analyses examining individuals with chronic medical conditions.

\section{METHODS}

\section{Data Source and Study Population}

We analyzed data from the National Health Interview Survey (NHIS) ${ }^{27}$ from 2015 to 2018 . The NHIS is an annual crosssectional, household in-person interview survey of a representative sample of the non-institutionalized US population. The household response rate for the NHIS during the study years ranged from $70.2 \%$ in $2015^{28}$ to $64.2 \%$ in $2018 .{ }^{29}$ Details of the structure, sampling frame, and survey items have been published previously. ${ }^{30}$

Our study sample included adults ages 18-64 with incomes of up to $400 \%$ of the FPL, the income range that includes individuals eligible for subsidized Marketplace coverage and Medicaid.

\section{Study Variables}

Our exposure was insurance type at the time of the survey. To provide a benchmark for Medicaid and Marketplace plans, we also compared each of these insurance types to ESI.

We examined outcomes in three domains: (1) barriers to health care access: having delayed or avoided care due to cost, that a provider's office would not accept the respondent's insurance, being unable to afford dental care, and being unable to afford to see a specialist when needed; (2) cost-related medication non-adherence: defined as either being unable to afford prescription medications, skipping medication doses to save money, taking less medicine to save money, or delayed filling of prescription to save money; and (3) financial strain: being very worried about not being able to pay the medical costs of a serious illness and of an accident, being very worried about not being able to pay the medical costs of normal health care, and, among those with continuous coverage under the same health plan for the last 12 months, having had problems paying medical bills in the last 12 months, having any out-of-pocket medical expenditures in the past 12 months, and having out-of-pocket medical expenditures exceeding \$2000 in the last 12 months.

We also identified a sub-group of respondents in the study sample who reported having at least one chronic medical condition: high blood pressure, high cholesterol, COPD, emphysema or chronic bronchitis, cerebrovascular disease or stroke, arthritis, cardiovascular disease, kidney disease, liver disease, diabetes, history of cancer, current asthma, or ulcer.

We obtained information on the following demographic variables and treated them analytically as indicated in parentheses: age (18-34, 35-44, 45-54, 55-64), sex (male vs female), race/ethnicity (Hispanic, White, Black, Asian, or other), marital status (currently married vs not married), educational attainment (less than high school, high school degree, some college, or more), annual family income as a percentage of the federal poverty level in a given year (14 categories of income), US census region (Midwest, Northeast, South, West), and NHIS survey year.

\section{Statistical Analyses}

We tabulated the proportion of each insurance group (Medicaid, Marketplace, and ESI) experiencing each outcome, and then estimated unadjusted and adjusted percentage point differences between each pair of insurance types, Marketplace vs Medicaid, Marketplace vs ESI, and Medicaid vs ESI. We derived adjusted estimates (predictive margins) using multiple linear probability regression models that included terms for potential confounders: age, sex, race/ethnicity, marital status, education level, employment status, FPL, census region, and NHIS survey year. Each regression includes the entire sample regardless of insurance type and includes dummy variables for each insurance type (ESI, Medicaid, Marketplace, as well as Uninsured, or Other). To obtain percentage point differences from linear models, we calculated the difference in the coefficients between the relevant groups. We calculated confidence intervals for these linear combinations of coefficients. We replicated all analyses using the sub-group of respondents with one or more chronic medical conditions. We excluded observations with missing data on model covariates from our analysis (Supplement Table 1).

Lastly, to examine more comparable groups, we conducted a sensitivity analysis replicating our main analysis after excluding all respondents with disabilities (defined as receiving supplemental security income). Additionally, because only Marketplace enrollees with incomes up to $250 \%$ of the FPL 
Table 1 Characteristics of the Study Population by Insurance Type: 2015-2018 National Health Insurance Survey

\begin{tabular}{|c|c|c|c|}
\hline & ESI $(n=23,202)$ & Medicaid $(n=10,963)$ & Marketplace $(n=3054)$ \\
\hline \multicolumn{4}{|l|}{ Age group, $n$ (weighted \%) } \\
\hline $18-34$ & $10,358(47.7)$ & $4166(40.1)$ & $815(28.3)$ \\
\hline $35-44$ & $4585(19.0)$ & $2183(19.9)$ & $542(18.0)$ \\
\hline $45-54$ & 4086 (16.6) & $2253(19.7)$ & $671(21.0)$ \\
\hline $55-64$ & $4173(16.7)$ & $2361(20.3)$ & $1026(32.8)$ \\
\hline Male, $n$ (weighted \%) & $10,555(46.6)$ & $3771(35.4)$ & $1262(42.4)$ \\
\hline \multicolumn{4}{|l|}{ Race/ethnicity, $n$ (weighted \%) } \\
\hline Non-Hispanic White & $15,007(64.1)$ & $5239(48.1)$ & $1908(62.1)$ \\
\hline Non-Hispanic Black & 3132 (14.9) & $2476(24.0)$ & $366(12.7)$ \\
\hline Hispanic & $3492(14.8)$ & $2448(21.6)$ & $552(17.7)$ \\
\hline Asian & $1290(5.2)$ & $476(4.2)$ & $205(6.8)$ \\
\hline \multirow{2}{*}{\multicolumn{4}{|c|}{ Marital status, $n$ (weighted \%) }} \\
\hline & & & \\
\hline Married & $9107(38.0)$ & $2513(22.5)$ & $1277(42.6)$ \\
\hline Other & $14,095(62.0)$ & $8450(77.5)$ & 1777 (57.4) \\
\hline \multicolumn{4}{|l|}{ Educational attainment, $n$ (weighted \%) } \\
\hline Less than high school graduate & $1726(6.9)$ & $2814(25.2)$ & $314(9.6)$ \\
\hline High school graduate & 5774 (24.6) & 3667 (33.6) & $845(27.6)$ \\
\hline Some college or more & $15,674(68.3)$ & $4427(40.8)$ & $1886(62.6)$ \\
\hline \multicolumn{4}{|l|}{ Percentage of federal poverty level, $\boldsymbol{n}$ (weighted \%) } \\
\hline $0-100 \%$ & $3251(14.4)$ & $5742(51.7)$ & $423(12.6)$ \\
\hline $101-250 \%$ & $8500(36.2)$ & $4303(39.6)$ & $1646(53.9)$ \\
\hline \multirow[t]{2}{*}{$251-400 \%$} & $11,451(49.4)$ & $918(8.7)$ & $985(33.5)$ \\
\hline & 49.4 & 8.7 & 33.5 \\
\hline Prescribed a drug in the past 12 months, $n$ (weighted \%) & $13,589(58.6)$ & $7453(68.0)$ & $1864(60.6)$ \\
\hline \multirow{2}{*}{\multicolumn{4}{|c|}{ Region, $n$ (weighted \%) }} \\
\hline & & & \\
\hline Northeast & $3235(15.1)$ & $2135(20.7)$ & $548(17.5)$ \\
\hline Midwest & $6069(27.2)$ & $2303(23.6)$ & $602(19.8)$ \\
\hline South & 8309 (37.1) & $3263(28.5)$ & $1211(41.9)$ \\
\hline West & $5589(20.5)$ & $3262(27.1)$ & $693(20.9)$ \\
\hline \multicolumn{4}{|l|}{ Gap in coverage over the last 12 months, $n$ (weighted \%) } \\
\hline Continuously insured with ANY plan & $21,563(93.1)$ & 9791 (89.6) & $2495(82.2)$ \\
\hline Continuously insured with THE SAME plan & $901(4.0)$ & $643(6.2)$ & $316(10.3)$ \\
\hline 6 months or longer gap in ANY coverage & $693(2.9)$ & $488(4.3)$ & $236(7.6)$ \\
\hline \multicolumn{4}{|l|}{ Employment status, $n$ (weighted \%) } \\
\hline Employed & $18,499(79.6)$ & 4403 (41.4) & $2121(69.4)$ \\
\hline Unemployed & $520(2.4)$ & 1149 (10.5) & $160(5.2)$ \\
\hline Out of the labor force & $4183(18.0)$ & $5411(48.1)$ & $773(25.4)$ \\
\hline \multicolumn{4}{|l|}{ Self-reported health status, $\boldsymbol{n}$ (weighted \%) } \\
\hline Excellent/very good & $15,090(65.0)$ & $4,147(37.8)$ & $1,817(59.5)$ \\
\hline Good/fair/poor & $8112(35.0)$ & $6816(62.2)$ & $1237(40.5)$ \\
\hline Disability (recipient of SSI), $n$ (weighted \%) & $154(0.7)$ & $1895(17.3)$ & $30(1.0)$ \\
\hline
\end{tabular}

Data source: 2015-2018 National Health Insurance Survey. Sample sizes for the total group include individuals with no insurance or insurance other than employer-sponsored insurance, exchange insurance, or Medicaid/public

ESI employer-sponsored insurance

*Chronic condition is defined as ever been told you have hypertension (high blood pressure), high cholesterol, stroke, COPD, emphysema or chronic bronchitis, cerebrovascular disease, arthritis, cardiovascular disease, kidney disease, liver disease, diabetes, history of cancer (excluding nonmelanomatous skin cancer), current asthma, or ulcer in the past 12 months

were eligible for cost-sharing subsidies, we compared the unadjusted prevalence of all outcomes between Marketplace enrollees with incomes up to $250 \%$ of the FPL versus above $250 \%$ of the FPL.

For all analyses, we used survey weights, primary sampling units and strata provided by the NHIS and procedures that account for the NHIS's complex sampling design to produce nationally representative estimates. Statistical significance was assigned at the $p=0.05$ level. We analyzed categorical variables using chi-square tests of independence. We used STATA (version 16.1) for all analyses. The Cambridge Health Alliance Institutional Review Board deemed this study exempt from human subjects review.

\section{Role of the Funding Source}

This study received no external funding.

\section{RESULTS}

\section{Sample Characteristics}

Our study sample with the key insurance types in our analysis (ESI, Medicaid, Marketplace) included 37,219 non-elderly adults with incomes $<400 \%$ of the FPL; 18,923 individuals had at least one chronic medical condition. Marketplaceinsured individuals were less likely than both those with Medicaid and ESI to be continuously insured (continuous coverage with any insurance plan for over 12 months) (Table 1). Respondents with Marketplace coverage were older, but otherwise more like those with ESI than Medicaid.

\section{Access to Health Care}

Marketplace enrollees were more likely than Medicaid enrollees to delay or avoid care due to cost $(19.3 \%$ vs $10.0 \%$; adjusted 
Table 2 Percentage with Difficulty Accessing Health Care in the Last 12 Months by Insurance Type

\begin{tabular}{|c|c|c|c|c|c|c|}
\hline & \multicolumn{3}{|c|}{ Unadjusted \% } & \multicolumn{3}{|c|}{ Adjusted difference \% $(95 \% \mathrm{CI})^{*}$} \\
\hline & ESI & Medicaid & Marketplace & ESI minus Medicaid & $\begin{array}{l}\text { ESI minus } \\
\text { Marketplace }\end{array}$ & $\begin{array}{l}\text { Medicaid minus } \\
\text { Marketplace }\end{array}$ \\
\hline All non-elderly adults & $\begin{array}{l}n= \\
23202\end{array}$ & $\begin{array}{l}n= \\
10963\end{array}$ & $n=3054$ & & & \\
\hline $\begin{array}{l}\text { Delayed or avoided care } \\
\text { due to cost }\end{array}$ & 11.3 & 10.0 & 19.3 & $2.3(1.3$ to 3.4$)$ & $-6.2(-7.9$ to -4.6$)$ & $-8.6(-10.4$ to -6.8$)$ \\
\hline $\begin{array}{l}\text { Insurance not accepted by } \\
\text { doctor or clinic }{ }^{\dagger}\end{array}$ & 2.8 & 8.8 & 10.1 & $-5.5(-6.4$ to -4.6$)$ & $-6.9(-8.3$ to -5.5$)$ & $-1.4(-3.1$ to 0.2$)$ \\
\hline $\begin{array}{l}\text { Could not afford to get } \\
\text { dental care }\end{array}$ & 10.1 & 19.8 & 20.0 & $-6.0(-7.1$ to -4.8$)$ & $-7.1(-8.8$ to -5.4$)$ & $-1.2(-3.1$ to 0.7$)$ \\
\hline $\begin{array}{l}\text { Could not afford to see a } \\
\text { specialist when needed? }\end{array}$ & 4.0 & 6.6 & 7.7 & $-0.6(-1.5$ to 0.2$)$ & $-2.4(-3.7$ to -1.1$)$ & $-1.8(-3.3$ to -0.3$)$ \\
\hline $\begin{array}{l}\text { Among those with } 1 \text { or } \\
\text { more chronic conditions }\end{array}$ & $\begin{array}{l}n= \\
10673\end{array}$ & $n=6563$ & $n=1687$ & & & \\
\hline $\begin{array}{l}\text { Delayed or avoided care } \\
\text { due to cost }\end{array}$ & 15.3 & 12.2 & 24.1 & $5.1(3.5$ to 6.8$)$ & $-7.1(-9.6$ to -4.6$)$ & $-12.2(-14.8$ to -9.5$)$ \\
\hline $\begin{array}{l}\text { Insurance not accepted by } \\
\text { doctor or clinic }{ }^{\dagger}\end{array}$ & 3.3 & 10.4 & 12.7 & $-6.0(-7.4$ to -4.6$)$ & $-8.9(-11.0$ to -6.7$)$ & $-2.9(-5.3$ to -0.5$)$ \\
\hline $\begin{array}{l}\text { Could not afford to get } \\
\text { dental care }\end{array}$ & 13.6 & 24.4 & 23.1 & $-5.8(-7.6$ to -4.0$)$ & $-6.8(-9.3$ to -4.4$)$ & $-1.1(-3.8$ to 1.7$)$ \\
\hline $\begin{array}{l}\text { Could not afford to see a } \\
\text { specialist when needed? }\end{array}$ & 6.2 & 8.9 & 9.9 & $0.4(-1.0$ to 1.9$)$ & $-2.5(-4.5$ to -0.5$)$ & $-2.9(-5.1$ to -0.7$)$ \\
\hline
\end{tabular}

Data source: 2015-2018 National Health Insurance Survey.

ESI employer-sponsored insurance

*Model adjusted for age, sex, racelethnicity, employment status, marital status, educational attainment, federal poverty level (using 14 income categories), region, and survey year

tReduced samples sizes as survey question was not asked in 2018

$\ddagger$ Chronic condition is defined as ever been told you have hypertension (high blood pressure), high cholesterol, stroke, COPD, emphysema or chronic bronchitis, cerebrovascular disease, arthritis, cardiovascular disease, kidney disease, liver disease, diabetes, history of cancer (excluding nonmelanomatous skin cancer), current asthma, or ulcer in the past 12 month

difference (AD) in percentage points, $8.6[95 \% \mathrm{CI}, 6.8-10.4)$ and were slightly more likely to report not being able to afford to see a specialist when needed (7.7\% vs $6.6 \%$; $\mathrm{AD}, 1.8[95 \% \mathrm{CI}$, $0.3-3.3]$ ), while there were no differences in the proportions whose insurance was accepted by a doctor or were unable to afford dental care (Table 2). ESI enrollees were also more likely to delay or forgo care due to cost than Medicaid enrollees in adjusted analyses (AD, 2.3 [95\% CI, 1.3-3.4]); however, for all other measures, ESI enrollees less frequently reported access barriers than either Marketplace or Medicaid enrollees.

Among the subset of individuals with at least one chronic medical condition, the proportions of respondents experiencing each barrier were higher for each insurance type than for the overall study population, and Medicaid-Marketplace

Table 3 Percentage with Cost-Related Medication Non-adherence in the Last 12 Months by Insurance Type (Defined as Either Not Being Able to Afford Getting a Prescription Medication, Skipping a Medication to Save Money, Took Less Medication to Save Money, or Delaying Filling a Prescription to Save Money)

\begin{tabular}{|c|c|c|c|c|c|c|}
\hline & \multicolumn{3}{|c|}{ Unadjusted \% } & \multicolumn{3}{|c|}{ Adjusted difference \% $(95 \% \mathrm{CI})^{*}$} \\
\hline & ESI & Medicaid & Marketplace & $\begin{array}{l}\text { ESI minus } \\
\text { Medicaid }\end{array}$ & $\begin{array}{l}\text { ESI minus } \\
\text { Marketplace }\end{array}$ & $\begin{array}{l}\text { Medicaid minus } \\
\text { Marketplace }\end{array}$ \\
\hline $\begin{array}{l}\text { Non-elderly adults prescribed } \\
\text { a medication in the last } 12 \\
\text { months }\end{array}$ & $n=13,587$ & $n=7447$ & $n=1864$ & & & \\
\hline $\begin{array}{l}\text { Could not adhere to prescribed } \\
\text { medications due to cost }\end{array}$ & 15.4 & 20.0 & 21.5 & $0.5(-1.0$ to 2.1$)$ & $-3.4(-5.7$ to -1.2$)$ & $-4.0(-6.4$ to -1.5$)$ \\
\hline $\begin{array}{l}\text { Among those with } 1 \text { or more } \\
\text { chronic conditions } s^{\dagger}\end{array}$ & $n=8216$ & $n=5481$ & $n=1335$ & & & \\
\hline $\begin{array}{l}\text { Could not adhere to prescribed } \\
\text { medications due to cost }\end{array}$ & 19.1 & 22.8 & 23.2 & $2.6(0.6$ to 4.7$)$ & $-1.7(-4.5$ to 1.0$)$ & $-4.3(-7.4$ to -1.3$)$ \\
\hline
\end{tabular}

Data source: 2015-2018 National Health Insurance Survey

ESI employer-sponsored insurance

*Adjusted for age, sex, racelethnicity, employment status, marital status, educational attainment, federal poverty level (using 14 income categories), region, and survey year

†Chronic condition is defined as ever been told you have hypertension (high blood pressure), high cholesterol, stroke, COPD, emphysema or chronic bronchitis, cerebrovascular disease, arthritis, cardiovascular disease, kidney disease, liver disease, diabetes, history of cancer (excluding nonmelanomatous skin cancer), current asthma, or ulcer in the past 12 months 


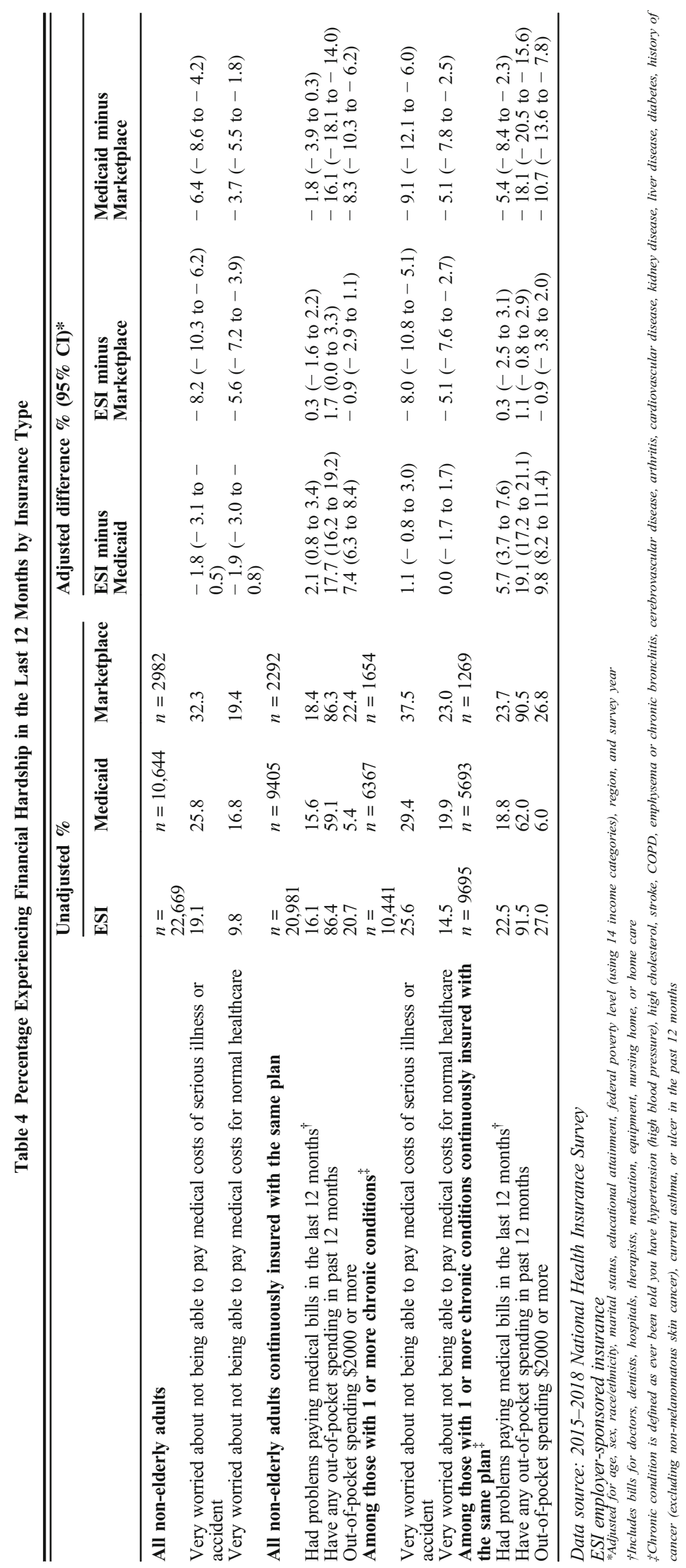


differences generally larger (Table 2). Among enrollees with chronic conditions, we also observed a pattern similar to the overall study population: ESI enrollees were more likely to delay or forgo care due to cost than Medicaid enrollees in adjusted analyses, and there was no significant difference in ability to afford a specialist. However, for all other measures, ESI enrollees less frequently reported access barriers than either Marketplace or Medicaid enrollees.

\section{Access to Medications}

In the overall study population, $21.5 \%$ of Marketplace and $20.0 \%$ of Medicaid enrollees experienced cost-related medication non-adherence (AD, 4.0 [95\% CI, 1.5-6.4]) (Table 3). ESI enrollees were less likely than Marketplace enrollees and as likely as Medicaid enrollees to experience this outcome in adjusted analyses. Among the chronic disease sub-group, we found a similar pattern of differences by insurance type, but larger proportions of enrollees in each insurance type experiencing cost-related non-adherence (ESI, 19.1\%; Medicaid, 22.8\%; and Marketplace, 23.2\%).

\section{Financial Strain}

Respondents enrolled in Marketplace plans experienced higher levels of medical financial strain than Medicaid enrollees for 4 of 5 of such measures in adjusted analyses (Table 4). For example, Marketplace enrollees were more likely than Medicaid enrollees to report being very worried about not being able to pay medical costs in case of a serious accident or illness $(32.3 \%$ vs $25.8 \%$; $\mathrm{AD}, 6.4$ [95\% CI, 4.2-8.6]) or for normal care $(19.4 \%$ vs $16.8 \%$; $\mathrm{AD}, 3.7$ [95\% CI, 1.8-5.5)]. ESI enrollees reported lower levels of worry than the enrollees of either of the other insurance types. A higher proportion of Marketplace than Medicaid enrollees also reported having any out-of-pocket medical expenses $(86.3 \%$ vs 59.1\%; AD, 16.1 [95\% CI, 14.0-18.1]) and expenses exceeding $\$ 2000$ (22.4\% vs 5.4\%; AD, 8.3 [95\% CI, $6.2-10.3]$ ). In adjusted analyses, a higher proportion of ESI than Medicaid enrollees also reported problems paying medical bills, any out-of-pocket medical spending, and spending exceeding $\$ 2000$ in the last 12 months. Finally, across all insurance groups, measures of financial strain were amplified among those with chronic conditions, in multivariable models. While we observed similar patterns among those with chronic diseases, insurance-type differences were typically even larger.

\section{Sensitivity Analyses}

In analyses that excluded individuals with disabilities, we found results similar to our main analyses (see Supplement Table 2). In comparisons between Marketplace enrollees with incomes up to $250 \%$ of the FPL versus over $250 \%$ of the FPL, access to dental care and concerns about medical costs were worse for those in the lower-income group; however, the higher-income group had more out-of-pocket spending (see Supplement Table 3).

\section{DISCUSSION}

Individuals with Marketplace coverage are substantially more likely to delay or avoid medical care due to cost, forego prescribed medications due to cost, and experience medical financial strain compared to those with Medicaid. Among individuals with at least one chronic medical condition, the prevalence of access barriers and financial strain are higher, and the differences between Medicaid and Marketplace enrollees are larger. For most outcomes, ESI enrollees experience better outcomes than either Marketplace or Medicaid enrollees, although for avoiding forgone care due to cost, and the out-of-pocket spending measures, Medicaid enrollees fare better than those with ESI.

Our findings are likely driven by several factors. First, Medicaid typically requires no or minimal cost sharing, whereas Marketplace plans often require considerable out-ofpocket payments for care, ${ }^{15,16,31}$ particularly for people with incomes above $250 \%$ of the FPL, who are ineligible for costsharing subsidies. ${ }^{9,}{ }^{17}$ Cost sharing, which has been shown to discourage the use of health care services among Marketplace enrollees in other studies, ${ }^{32}$ likely contributes to the greater avoidance of or delays in care, medication non-adherence, worry about medical bills, and out-of-pocket spending that we observed. Our finding that lower-income Marketplace enrollees eligible for cost sharing fared worse by some measures than higher-income Marketplace enrollees suggests that cost-sharing subsidies were insufficient to offset financial worries due to the lower income of this group. Second, many Marketplace plans have narrow provider networks, ${ }^{33}, 34$ leaving some enrollees with large medical bills for out-of-network care, or compelling others to delay or forgo care when innetwork providers are inaccessible. ${ }^{35,} 36$ Third, since Marketplace plan enrollees had lower rates of continuous coverage, health care costs incurred during gaps in coverage ${ }^{37}$ could have increased their financial strain. ${ }^{20}$ Given that dental coverage is not mandated as an essential health benefit in either Medicaid or Marketplace plans, ${ }^{38-40}$ predictably, enrollees from both plans had equal difficulty affording dental care in our study.

Our results are generally consistent with previous studies based on national samples, which demonstrated Medicaid's superior protections against experiencing cost-related medication non-adherence and financial strain. Two prior studies examined pre-post-ACA changes in measures of access and financial strain among individuals with incomes of $100 \%$ to $138 \%$ of the FPL - those who would have been eligible for Medicaid in Medicaid-expansion states and Marketplace plans in non-expansion states. These studies found that Medicaid- 
eligible individuals under the ACA had greater difficulty finding a provider ${ }^{22}$ but also experienced greater reductions in out-of-pocket payments ${ }^{21}{ }^{22}$ compared to Marketplace coverage-eligible individuals. These studies employed strong quasi-experimental methods that reduced confounding by factors associated with income differences between plan enrollees. Other studies examining similar outcomes in the post-ACA period have been limited to specific population sub-groups. One study of individuals with psychological distress found that Medicaid enrollees were less likely to experience access barriers or financial strain. Another study found no differences between Marketplace and Medicaid in California in access to primary and specialty providers or getting a timely doctor visit. $^{23}$

In addition, while previous studies have suggested that ESI plans provide better access to care than either Medicaid or Marketplace plans, ${ }^{23,}{ }^{24}$ our findings suggest that Medicaid outperforms ESI for low- to moderate-income people for several important outcomes related to expenditures: delaying or avoiding care due to cost, difficulty paying medical bills, and out-of-pocket medical spending. These findings on expenditures likely reflect the fact that Medicaid requires only minimal out-of-pocket spending whereas for ESI, at least some out-of-pocket spending for care is nearly universal. ${ }^{41}$ Furthermore, the share of privately insured Americans with high deductible health plans, and thus a higher chance of experiencing out-of-pocket spending, has been growing. ${ }^{42}$

Our analysis adds to the existing literature in several important ways. First, our study included individuals across the entire income spectrum of those eligible for Medicaid or Marketplace plans, rather than the narrow-income band used in some prior studies, increasing the generalizability of our findings. Inclusion of the full income spectrum also revealed that despite Marketplace enrollees' substantially higher incomes than Medicaid enrollees, their levels of financial strain and access were worse. Second, our study focuses not on assessing the impact of the ACA as originally implemented in 2014, as other studies have done, ${ }^{21,22}$ but rather on the recent effects of these plans as they have evolved since ACA implementation. These differences between Medicaid and Marketplace plans are most relevant for informing future health care coverage policies. Lastly, our findings uniquely highlight the even larger contrasts in access barriers and financial strain between Medicaid and Marketplace for people with chronic diseases, a group for whom barriers to care and financial strain may exact a particularly large toll.

Several study limitations should be noted. First, we were unable to control for characteristics of the Marketplace plans we examined, such as type of plan or metal tier. The plan definitions we used, however, have been used in prior research. ${ }^{24}$ Second, because publicly available NHIS files do not contain state identifiers, we could not control for statelevel fixed effects, Medicaid expansion status, or whether the state had a federal or state-based Marketplace. Third, selfreported outcomes in the NHIS are subject to recall bias. Lastly, there are likely differences between Medicaid, Marketplace plan, and ESI enrollees that we were unable to adjust for. For example, since Medicaid enrollees have reduced assets, potentially increasing their susceptibility to cost barriers to care and medical financial strain, our study may underestimate the difference in access to care and financial strain between Medicaid and Marketplace enrollees. While a substantially higher proportion of Medicaid enrollees have a disability, our sensitivity analysis excluding those with a disability yielded results comparable to our main analysis.

During the ACA's inception, proponents of private insurance expansion argued that inclusion of a Marketplace would result in better access to care because there was a perception that doctors would be more likely to see privately insured patients than those with Medicaid. Yet, our analysis suggests that many low- and moderate-income Americans experience barriers to seeing a doctor and substantial medical financial burdens, but that Medicaid offers better protection than Marketplace plans against these adverse outcomes. Several policy changes could be implemented within the current financing system to improve access and medically induced financial strain for enrollees. First, limiting the use of narrow networks in Marketplace plans could improve access and limit financial strain due to large out-of-pocket costs incurred at the point of service, although this might lead to premium increases. ${ }^{43}$ Second, increasing provider reimbursement rates for Medicaid (and potentially Marketplace plans), which are generally lower than those for other insurance types, ${ }^{44-46}$ could improve access. ${ }^{47}$ Third, policy makers could decrease out-of-pocket spending by enrollees in Marketplace plans by permanently increasing the cost-sharing subsidies for enrollees with incomes of $100-250 \%$ of the FPL, as some states have done, ${ }^{48}$, ${ }^{49}$ and by extending these subsidies to higher-income (250\% to $400 \%$ of the FPL) enrollees. The recently signed ARP temporarily expands Marketplace premium subsidies; however, there is no impact on plan out-of-pocket costs or network adequacy. Increased subsidies under ARP may reduce financial strain in the population we studied but are unlikely to improve access to care. Fourth, states that have not yet opted to expand Medicaid could do so, allowing many individuals with incomes of up to $138 \%$ of the FPL who currently have Marketplace plans (and those who are uninsured) to transition to Medicaid.

Broader reforms such as a Public Option or lowering the age of eligibility for Medicare are currently being debated by congress. However, the details of such proposals are not yet known, making the potential impact difficult to predict. A comprehensive "Medicare for all" plan, as proposed, ${ }^{50}$ would substantially reduce financial burdens and improve access to care; however, it currently lacks support from the current administration. While the ARP is likely to increase enrollment in Marketplace plans, our study suggests that these individuals 
would have better access to care and potentially less financial strain if they were to receive Medicaid instead.

Supplementary Information The online version contains supplementary material available at https://doi.org/10.1007/s11606-02107100-0.

\section{Contributors: None}

Corresponding Author: Sonali Saluja, MD, MPH; Gehr Center for Health Systems Science and Innovation, Keck School of Medicine of University of Southern California, Los Angeles, CA, USA (e-mail: sonali.saluja@med.usc.edu).

\section{REFERENCES}

1. Kominski GF, Nonzee NJ, Sorensen A. The affordable care act's impacts on access to insurance and health care for low-income populations. Annu Rev Public Health. 2017;38:489-505.

2. Goldman AL, Woolhandler S, Himmelstein DU, Bor DH, McCormick D. Out-of-pocket spending and premium contributions after implementation of the Affordable Care Act. JAMA Intern Med. 2018;178(3):347-55.

3. Shartzer A, Long SK, Anderson N. Access to care and affordability have improved following Affordable Care Act implementation; problems remain. Health Aff (Millwood). 2016;35(1):161-8.

4. McKenna RM, Langellier BA, Alcala HE, Roby DH, Grande DT, Ortega AN. The Affordable Care Act attenuates financial strain according to poverty level. Inquiry. 2018;55:46958018790164.

5. Miller S, Wherry LR. Health and access to care during the first 2 years of the ACA Medicaid expansions. N Engl J Med. 2017;376(10):947-56.

6. Goldman AL, McCormick D, Haas JS, Sommers BD. Effects of the ACA's health insurance marketplaces on the previously uninsured: a quasiexperimental analysis. Health Aff (Millwood). 2018;37(4):591-9.

7. Torres H, Poorman E, Tadepalli U, Schoettler C, Fung CH, Mushero N, et al. Coverage and access for Americans with chronic disease under the Affordable Care Act: a quasi-experimental study. Ann Intern Med. 2017;166(7):472-9.

8. Carman KG, Eibner C, Paddock SM. Trends in health insurance enrollment, 2013-15. Health Aff (Millwood). 2015;34(6): 1044-8.

9. Explaining health care reform: questions about health insurance subsidies. Henry J Kaiser Family Foundation. January 16, 2020. Available at: https://www.kff.org/health-reform/issue-brief/explaining-health-carereform-questions-about-health/\#

10. Biden health care proposal. Available at: https://joebiden.com/ healthcare/\#.

11. Keith K. Biden's first 100 days: the ACA and the American Families Plan. Health Affairs Blog. Available at: https://www.healthaffairs.org/do/10. 1377/hblog20210429.417119/full/. Accessed June19, 2021.

12. McDermott, Cox C, Rudowitz R and Garfield R. How has the pandemic affected health coverage in the U.S.? Henry J. Kaiser Family Foundation. December 9, 2020. Available at: https://www.kff.org/policy-watch/howhas-the-pandemic-affected-health-coverage-in-the-u-s/. Accessed June 19, 2021.

13. Keith K. American rescue plan increases ACA enrollment. Health Aff (Millwood). 2021:https://doi.org/10.1377/hlthaff202100983.

14. Coralo B and Rudowitz R. Analysis of recent national trends in Medicaid and CHIP enrollment. Henry J. Kaiser Family Foundation. June 17 2021. Available at: https://www.kff.org/coronavirus-covid-19/issuebrief/analysis-of-recent-national-trends-in-medicaid-and-chip-enrollment/. Accessed: June 17, 2021.

15. Thorpe KE, Allen L, Joski P. Out-of-pocket prescription costs under a typical silver plan are twice as high as they are in the average employer plan. Health Aff (Millwood). 2015;34(10):1695-703.

16. Polyakova M, Hua LM, Bundorf MK. Marketplace plans provide risk protection, but actuarial values overstate realized coverage for most enrollees. Health Aff (Millwood). 2017;36(12):2078-84.

17. Claxton G, Cox C, and Rae M. The cost of care with Marketplace coverage. Menlo Park,CA: Henry J. Kaiser Family Foundation, February 11, 2015. Available at: https://www.kff.org/health-costs/issue-brief/the-cost-ofcare-with-marketplace-coverage/.

18. Gable J, Whitmore H, Green M, Stromberg S, and Oran R. Consumer cost-sharing in Marketplace vs. employer health insurance plans, 2015
The Commonwealth Fund. December 21, 2015. Available at: https:// www.commonwealthfund.org/publications/issue-briefs/2015/dec/consumer-cost-sharing-marketplace-vs-employer-health-insurance.

19. Chen W, Page TF. Impact of health plan deductibles and health insurance marketplace enrollment on health care experiences. Med Care Res Rev. 2020;77(5):483-97.

20. McMorrow S, Kenney GM, Long SK, Gates JA. Marketplaces helped drive coverage gains in 2015; affordability problems remained. Health Aff (Millwood). 2016;35(10):1810-5.

21. Blavin F, Karpman M, Kenney GM, Sommers BD. Medicaid versus Marketplace coverage for near-poor adults: effects on out-of-pocket spending and coverage. Health Aff (Millwood). 2018;37(2):299-307.

22. Selden TM, Lipton BJ, Decker SL. Medicaid expansion and Marketplace eligibility both increased coverage, with trade-offs in access, affordability. Health Aff (Millwood). 2017;36(12):2069-77.

23. Alcala HE, Roby DH, Grande DT, McKenna RM, Ortega AN. Insurance type and access to health care providers and appointments under the Affordable Care Act. Med Care. 2018;56(2):186-92.

24. McKenna RM, Pintor JK, Ali MM. Insurance-based disparities in access, utilization, and financial strain for adults with psychological distress. Health Aff (Millwood). 2019;38(5):826-34.

25. Allen H, Gordon SH, Lee D, Bhanja A, Sommers BD. Comparison of utilization, costs, and quality of Medicaid vs subsidized private health insurance for low-income adults. JAMA Netw Open. 2021;4(1):e2032669.

26. Richard P, Walker R, Alexandre P. The burden of out of pocket costs and medical debt faced by households with chronic health conditions in the United States. PLoS One. 2018;13(6):e0199598.

27. National Center for Health Statistics. National Health Interview Survey, 2018. Public-use data file and documentation. https://www.cdc.gov/ nchs/nhis/data-questionnaires-documentation.htm. 2019.

28. National Center for Health Statistics. Paradata file description, National Health Interview Survey, 2015. Hyattsville, Maryland. 2016. ftp://ftp.cdc. gov/pub/Health_Statistics/NCHS/Dataset_Documentation/NHIS / 2015/srvydesc_paradata.pdf. Accessed January 23, 2021.

29. National Center for Health Statistics. Survey description, National Health Interview Survey, 2018. Hyattsville, Maryland. 2019. ftp://ftp.cdc.gov/ pub/Health_Statistics/NCHS/Dataset_Documentation/NHIS/2018/ srvydesc.pdf. Accessed January 23, 2021.

30. Center for Disease Control and Prevention. National Center for Health Statistics National Health Interview Survey. About the National Health Interview Survey. Accessed at: https://www.cdc. gov/nchs/nhis/about_nhis.htm.

31. Rosenkrantz AB, Sadigh G, Carlos RC, Silva E, 3rd, Duszak R, Jr. Out-ofpocket costs for advanced imaging across the US private insurance Marketplace. J Am Coll Radiol. 2018;15(4):607-14 el.

32. Kurt J. Lavetti, Thomas De Leire, Nicolas R. Ziebarth. How do low-income enrollees in the Affordable Care Act Marketplaces respond to costsharing? NBER Working Paper No. 26430. Issued in November 2019. Available at: https://www.nber.org/papers/w26430?sy=430.

33. Sen AP, Chen LM, Cox DF, Epstein AM. Most Marketplace plans included at least 25 percent of local-area physicians, but enrollment disparities remained. Health Aff (Millwood). 2017;36(9):1615-23.

34. Dorner SC, Jacobs DB, Sommers BD. Adequacy of outpatient specialty care access in Marketplace plans under the Affordable Care Act. JAMA. 2015;314(16):1749-50.

35. $\mathrm{Xu}, \mathrm{W} . Y$, , et al., Cost-sharing payments for out-of-network care in commercially insured adults. Am J Manag Care, 2019. 25(12): p. 598-604.

36. Sun, E.C., et al., Assessment of out-of-network billing for privately insured patients receiving care in in-network hospitals. JAMA Intern Med, 2019. 179(11):1543-1550

37. Abdus S. Part-year coverage and access to care for nonelderly adults. Med Care. 2014;52(8):709-14.

38. Medicaid benefits: dental services. Henry Kaiser Family Foundation, 2018. Available at : https://www.kff.org/medicaid/state-indicator/dental-services/? current Timeframe $=0$ \& s or t M od el=\% 7 B $\% 22$ colld $\% 22$ : \%22Location\%22,\%22sort $\% 22: \% 22$ asc $\% 22 \% 7 \mathrm{D}$.

39. Elizabeth Hinton and Julia Paradise . Access to dental care in Medicaid: spotlight on nonelderly adults. ar 17, 2016. Available at: https://www.kff. $\mathrm{org} /$ medicaid/issue-brief/access-to-dental-care-in-medicaid-spotlighton-nonelderly-adults/.

40. Kamyar Nasseh, PhD; Marko Vujicic, PhD. Dental plan premiums in the Affordable Care Act marketplaces trended downward from 2014 through 2016. JADA 148(4):230-235 http://jada.ada.org April 2017. Available at: https://jada.ada.org/article/S0002-8177(16)30964-3/pdf. 
41. Medicaid.gov. Cost sharing out of pocket costs. https://www.medicaid gov/medicaid/cost-sharing/cost-sharing-out-pocket-costs/index.html. Accessed January 23, 2021.

42. Cohen R, Martinez M, Zammitti E. Health insurance coverage: early release of estimates from the National Health Interview Survey, 2018. Natioinal Center for Health Statistics. Available at: https://www.cdc.gov/ nchs/data/nhis/earlyrelease/Insur201808.pdf.

43. Polsky D, Cidav Z, Swanson A. Marketplace plans with narrow physician networks feature lower monthly premiums than plans with larger networks. Health Aff (Millwood). 2016;35(10):1842-8.

44. Norton S, Zuckerman S. Trends in Medicaid physician fees, 1993-1998. Health Aff (Millwood). 2000;19(4):222-32.

45. Zuckerman S, McFeeters J, Cunningham P, Nichols L. Changes in medicaid physician fees, 1998-2003: implications for physician participation. Health Aff (Millwood). 2004;23:Suppl Web Exclusives:W4-374-84.
46. Biener AI, Selden TM. Public and private payments for physician office visits. Health Aff (Millwood). 2017;36(12):2160-4.

47. Polsky D, Richards M, Basseyn S, Wissoker D, Kenney GM, Zuckerman $\mathrm{S}$, et al. Appointment availability after increases in Medicaid payments for primary care. N Engl J Med. 2015;372(6):537-45.

48. State-funded premium subsidies make coverage more affordable; statefunded CSRs make silver plans especially valuable. Health Insuranc.org Website. Available at: https://www.healthinsurance.org/vermont-statehealth-insurance-exchange/\#CSR.

49. Massachusetts health insurance marketplace: history and news of the state's exchange. Healthinsurance.org website. Availble at: https://www. healthinsurance.org/massachusetts-state-health-insurance-exchange/.

50. Medicare for All Act of 2021, 117th Congress (2021-2022). Available at https://www.congress.gov/bill/117th-congress/house-bill/ 1976. Accessed July 23, 2021. .

Publisher's Note: Springer Nature remains neutral with regard to jurisdictional claims in published maps and institutional affiliations. 